\title{
A "governança empresarial" das metrópoles sob o predomínio neoliberal: o papel da gestão pública gerencial e da privatização do sistema político
}

\author{
The "business governance" of metropolises under neoliberal \\ predomination: the role of managerial public administration \\ and of privatization of the political system
}

Francisco César Pinto Fonseca [l]

\section{Resumo}

Este artigo objetiva analisar conceitualmente as seguintes variáveis incidentes à formação da governança neoliberal nos regimes urbanos no Brasil: os pressupostos conceituais do neoliberalismo hayekiano; o papel das Organizações Sociais (OSs) e das Organizações da Sociedade Civil de Interesse Público (Oscips), advindas da reforma gerencial do Governo Fernando Henrique Cardoso; os diversos instrumentos gerenciais privados atuantes no Estado, nas dimensões meio (gestão) e fim (políticas públicas), entre os quais as Parcerias Público-Privadas e os regimes de concessão; os pilares privatizantes do sistema político brasileiro; e a financeirização dos instrumentos e políticas urbanos. Conclui-se que todos esses instrumentos se sobrepõem ao planejamento público no Brasil, tornando a governança dos regimes urbanos semelhante ao que Dardot e Laval (2016) chamaram de "governo empresarial".

Palavras-chave: governança neoliberal; metrópoles; reforma gerencial; financeirização e governo empresarial.

\begin{abstract}
This article aims to analyze conceptually the following variables influencing the formation of neoliberal governance in urban regimes in Brazil: the conceptual assumptions of the Hayekian neoliberalism; the role of Social Organizations and of Civil Society Organizations of Public Interest (known as Oscips), which arose from the managerial reform of Fernando Henrique Cardoso's government; the various private management instruments operating in the State, in the dimensions related to management and public policies, including Public-Private Partnerships and concession schemes; the privatizing pillars of the Brazilian political system; and the financialization of urban policies and instruments. It is concluded that all these instruments overlap with public planning in Brazil, making the governance of urban systems be similar to what Dardot and Laval (2016) called "business governance".
\end{abstract}

Keywords: neoliberal governance; metropolises; managerial reform; financialization and business governance. 


\section{Introdução e problematização}

Este artigo objetiva analisar os padrões neoliberais ${ }^{1}$ instituídos na gestão pública brasileira desde a Reforma do Estado, promovida pelo Governo Fernando Henrique Cardoso (FHC), em 1995, no contexto da New Public Management. contratualização entre órgãos do Estado e agentes privados, com ou sem interesses lucrativos, por meio das Organizações Sociais (OSs) e das Organizações da Sociedade Civil de Interesse Público (Oscips), e sobretudo lógicas, técnicas e ferramentas gerenciais advindas da administração privada e transpostas à administração pública que vêm implicando a "contratualização" da administração e dos serviços públicos com agentes privados. Mais ainda, o amplo processo de participação de atores privados tanto nas áreas meio (gestão) como nas áreas fins (políticas públicas) da Administração Pública tem sido a tônica desde a reforma gerencial. Nas áreas fins, destaque deve ser dado às Parcerias-Público Privadas (PPPs), que são, por sua vez, viabilizadas por intensos processos financeirizados, assim como a participação sistêmica de todo tipo de consultorias privadas nas etapas da gestão pública: áreas meio e áreas finalísticas.

A origem desse processo remonta aos anos 1990, quando o Governo FHC intentou adotar padrões empresariais à gestão pública: conceitos como "eficiência" e "eficácia" nas atividades das aludidas áreas "meio" (processos de gestão) e nas atividades "fim" (políticas públicas e outras ações finalísticas do ato de governar), entre outros. Tal dimensão gerencial tem levado a regimes de governança denominados por Dardot e Laval (2016) "governo empresarial", isto é, a vigorosa privatização da governança, com efeitos contrários aos códigos legais, como a Constituição Federal, o Estatuto das Cidades e diversos outros normatizadores dos regimes urbanos.

Mas, para além do governo federal (Poder Executivo), tais padrões empresariais inscrevem-se na dinâmica e na estrutura do Estado brasileiro, nos três níveis da federação, particularmente nos correspondentes poderes Executivos. Tais padrões têm, portanto, perpassado governos de distintas colorações partidárias/ideológicas, como o PSDB (centro-direita) e o PT (centro-esquerda), no plano federal, e os mais diversos partidos nos planos estaduais e municipais.

Além das OSs, das Oscips e das Parcerias Público-Privadas (PPPs), os regimes de concessão (de equipamentos e de serviços públicos), as infindáveis "consultorias" e "assessorias" privadas, que majoritariamente inserem visões/ instrumentos privatistas à esfera pública, e as diversas formas de atuação do setor privado seja com ou sem fins lucrativos -, denominados genérica e ideologicamente "terceiro setor", vêm solidificando o caráter híbrido da administração pública. Nesta, há predomínio privado e, particularmente, na governança das metrópoles impõe-se a "gestão por resultados", cujas métricas são vigorosamente advindas do setor privado. Igualmente, as chamadas "Operações Urbanas Consorciadas" transferem, em larga medida, a intervenção pública nas zonas urbanas ao empresariado disposto a "investir" nas políticas "públicas" urbanas.

Esse quadro se completa com a histórica "privatização da vida política" brasileira, vigente particularmente desde a redemocratização, devido à combinação entre multipartidarismo 
flexível, necessidade de maiorias parlamentares para governar, financiamento privado (legal e ilegal) de campanhas e partidos e instituições pouco republicanas.

Dessa forma, a análise do sistema político brasileiro, em consonância com a introdução das OSs e das Oscips - e suas consequências -, intenta formar quadro analítico do "governo empresarial" no Brasil, por sua vez articulado à financeirização das políticas no ambiente urbano.

Por fim, antes de analisar esse conjunto de questões que compõem a governança neoliberal, analisar-se-ão alguns pressupostos do ultraliberalismo como forma de balizar a reflexão acerca da governança nos regimes urbanos.

\section{Metodologia}

0 tema da governança empresarial sob o regime neoliberal das (macro)metrópoles será analisado conceitualmente da seguinte forma: a) exame dos pressupostos do pensamento neoliberal, notadamente de Hayek; b) análise conceitual de características, objetivos e modus operandi da reforma gerencial, iniciada em 1995 e que se incrustou nas estruturas do Estado brasileiro nos três níveis da federação. Serão examinados particularmente os pressupostos legais/conceituais dos "contratos de gestão" estabelecidos entre agentes privados, com ou sem fins lucrativos, que foram (re)ordenados como Organizações Sociais (OSs) e como Organizações da Sociedade Civil de Interesse Público (Oscips), mas também as Parcerias Público Privadas (PPPs), entre outras; c) análise conceitual dos pilares do sistema político brasileiro desde a redemocratização até o golpe parlamentar de 2016. Pretende-se demonstrar o caráter privatizante e conservador do sistema partidário e eleitoral, por meio dos seguintes aspectos, entre outros: extrema flexibilização partidária de matriz conservadora, financiamento privado de campanhas e partidos, coligações partidárias heterogêneas para adquirirem tempo de propaganda no rádio e na tv e para governar, o que implica articulação de interesses contraditórios; e d) reflexão acerca do papel da financeirização no ambiente urbano. Portanto, pretende-se refletir sobre como os regimes urbanos são impactados pela governança neoliberal e vice-versa, num complexo contraditório, mas com predominância do grande capital.

\section{Pressupostos do ultraliberalismo}

Existem várias concepções de sociedade erigidas pelas mais diversas doutrinas políticas. Mesmo no interior do pensamento liberal há compreensões diversas, casos das perspectivas de S. Mill, Tocqueville, Rawls, Sen e Dworkin, entre tantos outros. Nesta seção objetiva-se analisar os pressupostos doutrinários do neoliberalismo de corte econômico que, embora tenha esse viés, pressupõem crenças filosóficas. Expõe-se aqui, de forma panorâmica, a chamada escola Austríaca que, por seu turno, influenciou outras escolas doutrinárias - as assim chamadas "escolas" de Chicago e de Virgínia, como são conhecidas - e são confluentes em vários aspectos, notadamente quanto à defesa do individualismo e do mercado, em detrimento dos direitos coletivos, do papel do 
Estado como indutor do desenvolvimento e do Estado de Bem-Estar Social. Todas elas têm na figura de F. A. Von Hayek sua grande referência original.

Daí a análise da escola Austríaca ser fundamental para que se conheçam as balizas filosóficas e ideológicas das correntes que ascenderam ao poder no século XX e mudaram radicalmente os rumos de governos e populações, e que estão mais do que nunca presentes no mundo contemporâneo. ${ }^{2}$ Afinal, a ascensão do que genericamente se chama de neoliberalismo se deu no contexto da crescente intervenção estatal, mesmo em países de forte tradição liberal - caso dos EUA e da Inglaterra -, e representou o ocaso do paradigma keynesiano vigente em larga escala durante o século XIX: tal paradigma foi substituído por políticas informadas pelo laissez-faire e pela "mão invisível do mercado".

Finda a Segunda Guerra, por meio do Plano Marshall efetivou-se enorme ajuda estadunidense aos países envolvidos no conflito, consolidando, portanto, o papel central ocupado pelo Estado tanto à reconstrução das economias e sociedades destruídas como à promoção de um novo e estável ciclo de crescimento econômico, mas que se preocupasse, em certa medida, com a distribuição da renda. Dessa forma, por mais que certa desconfiança em relação às virtudes do "mercado livre" estivesse se constituindo, a ponto de se estabelecer ambiente ideológico e sociointelectual pró-intervenção do Estado, será fundamentalmente a combinação entre o keynesianismo e o legado de lutas socialistas o movimento responsável por conferir organicidade teórica e vigor ideológico às reformas econômicas e sociais, que foram posteriormente efetivadas pelos diversos Estados nacionais, num contexto internacional marcado pela reconstrução econômica e política. Pretendia-se, portanto, a superação das causas que levaram tanto à grande depressão econômica quanto (no que tange aos fatores econômicos) à guerra, ao mesmo tempo que se construía um "novo" mundo com direitos sociais universalizados. 0 acordo de Bretton Woods, firmado nos momentos finais da guerra, foi o marco desse processo de reconstrução econômica e política, confluente à elaboração da nova ordem internacional hegemonizada pelos EUA. Foram estabelecidas medidas voltadas ao controle do capital financeiro e do mercado, pois o espírito que presidiu a reunião, na qual Keynes foi um dos principais nomes, desconfiava das virtudes intrínsecas do mercado, embora defendesse a ordem "liberal" em perspectiva mundial, tendo conseguido estabelecer certas previsibilidade e estabilidade internacionais que permitiram o maior crescimento econômico contínuo do capitalismo. As ideias e os dogmas dos neoliberais foram derrotados nesse momento - final da Segunda Guerra Mundial, embora estivessem em processo de corrosão desde o final do século XIX -, mas ressurgiram com força nos anos 1970 ao chegarem ao poder, tornando-se hegemônicas na década de 1980, inserindo-se na agenda mundial até os dias de hoje.

Nesse contexto de resistência antiestatal e antissocial neoliberal, paulatinamente seus próceres foram se apropriando de instituições que funcionavam como - na perspectiva gramsciana - "aparelhos privados de hegemonia". ${ }^{3}$ Assim, ao longo do tempo, importantes ideias-força desenvolvidas por intelectuais dessa corrente foram personificadas em propostas e programas de governo. Podem ser assim compreendidas: desestatização da economia, 
privatizando-se todas as empresas sob controle do Estado; preponderância da esfera privada (o indivíduo "livre" no mercado) sobre a esfera pública; desestruturação do Estado de Bem-Estar Social, uma vez que concebido (e estigmatizado) como ineficaz, ineficiente, perdulário, injusto e autoritário (por transferir aos mais pobres parcelas de renda dos mais ricos ou "bem-sucedidos", que assim o seriam por seus próprios méritos), e indutor de comportamentos que não valorizariam o mérito e o esforço pessoais; fim da proteção aos capitais nacionais, que deveriam competir livremente com seus congêneres estrangeiros; desregulação e desregulamentação da produção, da circulação dos bens e serviços, do mercado financeiro e das relações de trabalho; pressão pela quebra do pacto corporativo entre capital e trabalho, em nome da liberdade de escolha individual e da soberania do consumidor; associação entre o conceito de liberdade ao de mercado, isto é, "liberdade de mercado" ou ausência de empecilhos à relação capital/trabalho e à livre realização dos fatores produtivos; valorização das "virtudes" do livre mercado, em dois sentidos: como instrumento prodigioso para aumentar a riqueza - gerando suposta "natural" distribuição de renda, em razão do aumento da produtividade - e como único mecanismo possível de refletir os preços reais dos produtos e serviços, possibilitando aos indivíduos o exercício de cálculos em relação à atividade econômica; concepção de democracia unicamente como possibilitadora do mercado livre e da liberdade individual; postulação de que o Estado deveria oferecer a cada indivíduo - em relação a políticas públicas e a sistemas de seguridade - apenas e tão somente o quanto (mensurado monetariamente) cada um contribuísse para tanto.
Esse conjunto de pressuposições neoliberais, tomados como agenda de reformas, afirma ser o Estado intrinsecamente produtor de inúmeras crises: fiscal/orçamentária, ético/política, burocrático/administrativa, de produtividade/ competição, entre inúmeras outras.

Em razão disso surgem, no amplo leque do que se intitulou "reformas do Estado orientadas para o mercado": a pressão pela diminuição dos gastos governamentais e pela diminuição de impostos aos mais ricos; a valorização de funções essencialmente "mínimas" do Estado: isto é, a garantia, por meio da criação de "normas gerais e abstratas", da ordem e da paz, da propriedade privada, dos contratos livremente elaborados entre os indivíduos e do livre mercado, mediante a proibição de práticas anticoncorrenciais (desconsiderando-se, dessa forma, o fato de o capitalismo contemporâneo ser essencialmente oligopólico); a promoção da desregulamentação, desregulação e flexibilização dos mercados (de capitais, produtivo e de trabalho); e a valorização do sistema jurídico, supostamente neutro, uma vez que estruturante da sociedade composta por indivíduos autônomos em suas ações em busca de seus interesses.

Parte significativa dessas concepções se constituiu em agenda concreta de reformas, propugnada principalmente pelos think-tanks e transmitidas pelos aparelhos privados de hegemonia, tais com a mídia, as universidades e o complexo da propaganda e publicidade. Tais pontos dessa agenda foram adaptados a cada país, conservando-se, contudo, tanto as matrizes como o ethos que as presidem. Embora raramente tenha havido programa neoliberal em sociedades concretas, e possivelmente seja inaplicável, ${ }^{4}$ em razão da complexidade das 
sociedades contemporâneas - eivadas de interesses diversos e contraditórios -, do caráter não realista das proposições dessa corrente e da vinculação entre os capitais privados ao Estado, ele representa muito mais um vetor do que propriamente um programa aplicável. Portanto, toma-se aqui o programa neoliberal mais como tipo ideal, espécie de carta de intenções, do que propriamente projeto aplicável. Apesar dessas ressalvas, a capacidade dessa corrente de persuadir e inspirar governos, agências, instituições (nacionais e internacionais) e, em certas situações, pessoas simples é notável.

Nesse processo de disputas políticos/ ideológicas/históricas, é significativo observar o papel ultraliberal exercido pela Sociedade Mont Pèlerin, cujos encontros se realizam anualmente até hoje, tendo ocorrido no Brasil em 1993. 0 intuito dessas reuniões é, após terem se constituído em "internacionais liberais", espraiar e inculcar ideias liberais a partir de um núcleo duro doutrinário, à guisa do que fizeram os socialistas. Segundo Cockett (1995, p. 34),

\section{[...] in Hayek's opinion, regularly} and successfully acted as if they fully understood the key position of the intellectuals and have directed their main efforts towards gaining the support of the "elite", which was certainly true of the Fabians and Keynes in Britain. ${ }^{5}$

Mas, para além da disputa pelas ideias-chave no mundo, segundo Cockett: For Hayek, "what to the contemporary conflicting interests decided by the vote of the masses, has usually been decided long before in a battle of ideas confined to narrow circles" (ibid., pp. 104 e 105). Hayek procurou justificar a superioridade do modo de produção capitalista e das virtudes do mercado livre em relação tanto aos sistemas mistos, caso da social democracia, como principalmente ao socialismo. A desigualdade social resultante da sociedade ultraliberal individualista e possessiva fora justificada, uma vez que supostamente inerente às qualidades distintas dos homens. Num mundo marcado pelos traumas da depressão mundial, do desemprego e de guerras mundiais - entre as décadas de 1910 e 1940 -, tais posições foram defendidas tenazmente, assemelhando-se ao fundamentalismo religioso, tal como ainda hoje se apresentam. Afinal, quanto mais a realidade se mostrava antitética a esses valores, mais eram ratificados, propugnados e, no limite, reificados. Caso paradigmático desse ethos é o tema da "justiça social" que, embora crucial e decisivo naquele momento histórico, foi considerado por Hayek "sem significação" em sociedades que se requeriam livres. Para o autor,

[...] a questão precedente é saber se é moral que os homens sejam submetidos aos poderes de direção que teriam de ser exercidos para que os benefícios obtidos pelos indivíduos pudessem ser significativamente qualificados de justos e injustos. Deve-se admitir, é claro, que o modo pelo qual os benefícios e ônus são distribuídos pelo mecanismo do mercado deveriam, em muitos casos, ser considerados muito injustos se resultassem de uma alocação deliberada a pessoas específicas. Mas não é este 0 caso. Essas cotas são resultado de um processo cujo efeito sobre pessoas específicas não foi nem pretendido nem previsto por ninguém quando do surgimento das instituições - as quais puderam então continuar existindo por se ter constatado que proporcionavam a todos, ou à maioria, melhores perspectivas de satisfação das suas necessidades. Exigir justiça de semelhante processo é 
obviamente absurdo, e selecionar algumas pessoas numa tal sociedade como fazendo jus a uma parcela específica é evidentemente injusto. (Hayek, 1985, p. 82)

Para Hayek, como se observa, o mercado seria o único mecanismo possível de distribuição - natural e espontânea - de renda. Os que demandassem por "justiça social", ou seja, por intervenção (considerada essencialmente autoritária) do Estado com vistas a retirar recursos dos que "se saíssem melhor" no mercado ou simplesmente fossem mais afortunados, e repassá-los aos "fracassados" (isto é, aos pobres), não teriam compreendido o seu funcionamento. 0 aspecto crucial é o mercado não ser concebido como justo ou injusto, pois seu papel seria apenas o de coordenar os agentes produtivos, cabendo a estes, pelo mérito, promover a "justiça", isto é, a ascensão social "meritocrática" em razão da ação individual. Daí o aludido papel essencialmente "regulatório" a ser desempenhado pelo Estado quanto ao cumprimento dos contratos efetivados entre as partes livres.

Assim, afirma Hayek no livro que marcou o pensamento ultraliberal, intitulado 0 caminho da servidão, escrito em 1944, já como resistência ao novo intervencionismo que rapidamente se consolidava:

0 Estado deve limitar-se a estabelecer normas aplicáveis a situações gerais, deixando os indivíduos livres em tudo que depende das circunstâncias de tempo e lugar, porque só os indivíduos poderão conhecer plenamente as circunstâncias relativas a cada caso e a elas adaptar suas ações [...]. Num mundo em que tudo fosse previsto com exatidão, o Estado dificilmente poderia agir e, ao mesmo tempo, ser imparcial. (Ibid., 1987, pp. 88-89)
Como se observa, o Estado "intervencionista" (keynesiano ou social-democrata) é concebido como supressor das liberdades individuais, notadamente o chamado "Estado previdenciário" do pós-guerra que, além do mais, foi criticado como "paternalista": termo estigmatizado pelo radicalismo liberal. Trata-se, em verdade, de aguçamento da crítica ao Estado redistribuidor, uma vez que se compara a proteção social do Estado à de um pai arbitrário. Assim, para Hayek,

Se o governo não deseja apenas facilitar aos indivíduos a conquista de certos padrões de vida, mas também garantir que todos os conquistem, só poderá fazê-lo privando os indivíduos de qualquer escolha neste sentido. 0 Estado previdenciário torna-se, assim, um Estado familiar no qual um poder paternalista controla a maior parte da renda da comunidade, alocando-a entre os indivíduos nas formas e quantidades que julga compatíveis com sua necessidade ou mérito. (Ibid., 1983, p. 316)

Portanto, o movimento neoliberal, como opositor radical das ideias sociais e intervencionistas predominantes, atuaria vigorosamente para evitar que as sucessivas intervenções do Estado na economia levassem os países sobretudo na Europa e nos EUA, paulatinamente e sem que seus povos e líderes se apercebessem - à "servidão", tomada retoricamente sinônimo de socialismo. Para Hayek, se o Estado interviesse em inúmeros setores, desorganizaria estruturalmente a produção, deixando de intervir onde, de fato, deveria fazê-lo, isto é, nos sindicatos. Afinal, esses são concebidos "agentes monopolistas", pois, além de controlarem - supostamente - a força de trabalho, imporiam greves e piquetes, desconsiderando, 
com isso, a característica básica do salário: ser um preço, como qualquer outro. Em outras palavras, não deveria haver salários mínimos ou mesmo salários profissionais. Para Hayek,

Embora, na realidade, as conquistas obtidas pelos sindicatos com sua política salarial sejam muito menores do que geralmente se supõe, apesar disso suas atividades nesse campo são muito prejudiciais do ponto de vista econômico e extremamente perigosas do ponto de vista político. . [...] embora pouco se deva esperar de qualquer ação específica do governo contra o monopólio da iniciativa [empresarial], a situação é diferente nos casos em que os governos deliberadamente promoveram o crescimento do monopólio e até deixaram de exercer a função primordial de governo - a prevenção da coerção -, permitindo exceções às normas legais gerais, como vêm fazendo, há muito, no campo do trabalho. (Ibid., pp. 330 e 322)

Como se observa, o radicalismo ultraliberal despreza um elemento crucial das sociedades industriais: o fato de a força de trabalho ter poder infinitamente menor do que o dos detentores do capital. Logo, o veto à organização sindical denota forte caráter conservador, e mesmo reacionário, afastando-se das vertentes mais democráticas surgidas no seio do liberalismo no século XIX. Mas é fundamental à compreensão das estratégicas contra hegemônicas neoliberais observar que Hayek - assim como outros ideólogos dessa doutrina - tinha absoluta convicção de que o embate que travava era, antes de tudo, ideológico, pois voltado à constituição de nova hegemonia. Esta, para que se realizasse, deveria demonstrar e enfatizar as falhas e os equívocos do então consenso dominante (keynesiano), bem como provar a superioridade do (ultra)liberalismo. Por isso,
Hayek, em Os fundamentos da liberdade, deixa clara a importância do referido embate, uma vez que o vencer implicaria a conquista das "mentes e dos corações". Impressiona a contemporaneidade dessa assertiva:

Na luta pelo apoio moral dos povos do mundo, a falta de uma sólida filosofia deixa o Ocidente em grande desvantagem. Há muito que o estado de espírito de seus líderes intelectuais se vem caracterizando pela desilusão com seus princípios, pelo desprezo por suas realizações e pela preocupação exclusiva com a criação de "mundos melhores" [leia-se socialismo e intervencionismo]. Não é com esse estado de espírito que se pode esperar ganhar adeptos. Se quisermos vencer a grande luta que se está travando no campo das ideias, devemos, antes de mais nada, saber em que acreditamos. Devemos também ter ideia clara daquilo que desejamos preservar, se não quisermos perder o rumo. [...] nossa própria sobrevivência pode depender de nossa capacidade de congregar uma parte suficientemente significativa do mundo em torno de um ideal comum). [...] devemos esperar que, aqui, ainda exista um amplo consenso com respeito a certos valores fundamentais. Mas esse consenso já não é mais explícito; e, para que tais valores voltem a predominar, há urgente necessidade de sua reafirmação e defesa. (Ibid., pp. XXXII e XXXIII)

Essa passagem ilustra cabalmente o caráter da disputa político-ideológica vigente durante todo o século $X X$, que se mantém - renovada - até os dias de hoje, em que as velhas ideias ultraliberais, ao tentarem transparecer como "modernas", apenas expressam todo o elitismo, o reacionarismo (pois reativa à sociedade de direitos) e seu compromisso como o capital em detrimento dos trabalhadores. 
Vejamos como esses pressupostos ultraliberais impactam a governança das metrópoles.

\section{A reforma gerencial e a criação de Organizações Sociais (OSs) e das Organizações da Sociedade Civil de Interesse Público (Oscips): características e dinâmicas}

Em contraposição às formas societais de gestão pública (Paes de Paula, 2005), o gerencialismo é atinente às aludidas "reformas orientadas para o mercado", por sua vez sustentáculo do capitalismo flexível. Mesmo que, no Brasil, tenha sido originalmente proposto em bases democráticas (embora não necessariamente participativas), o fato é que sua origem é proveniente do ultraliberalismo. Como se observa pelos novos marcos jurídicos criados durante 0 Governo FHC, a justificativa para a introdução de atores privados na administração pública e nas políticas públicas dá-se a partir da consideração sobre "Setores do Estado e Formas de Propriedade". Assim define o texto que instituiu esses novos atores no setor público:

Outra distinção importante é a relacionada às formas de propriedade. Ainda que vulgarmente se considerem apenas duas formas, a PROPRIEDADE ESTATAL e a PROPRIEDADE PRIVADA, existe no capitalismo contemporâneo uma terceira forma, intermediária, extremamente relevante: a PROPRIEDADE PÚBLICA NÃO ESTATAL, constituída pelas organizações sem fins lucrativos, que não são propriedade de nenhum indivíduo ou grupo e estão orientadas diretamente para 0 atendimento do interesse público. 0 tipo de propriedade mais indicado variará de acordo com o setor do aparelho do Estado.

No núcleo estratégico a propriedade tem que ser necessariamente estatal. Nas atividades exclusivas de Estado, onde 0 poder extroverso de Estado é exercido, a propriedade também só pode ser estatal. Já para o setor não exclusivo ou competitivo do Estado a propriedade ideal é a pública não estatal. Não é a propriedade estatal porque aí não se exerce o poder de Estado. Não é, por outro lado, a propriedade privada, porque se trata de um tipo de serviço por definição subsidiado.

A propriedade pública não estatal torna mais fácil e direto o controle social, através da participação nos conselhos de administração dos diversos segmentos envolvidos, ao mesmo tempo que favorece a parceria entre sociedade e Estado. As organizações nesse setor gozam de uma autonomia administrativa muito maior do que aquela possível dentro do aparelho do Estado. Em compensação seus dirigentes são chamados a assumir uma responsabilidade maior, em conjunto com a sociedade, na gestão da instituição. No setor de produção de bens e serviços para o mercado a eficiência é também o princípio administrativo básico e a administração gerencial, a mais indicada. Em termos de propriedade, dada a possibilidade de coordenação via mercado, a propriedade privada é a regra. A propriedade estatal só se justifica quando não existem capitais privados disponíveis - o que não é mais o caso no Brasil - ou então quando existe um monopólio natural.

Mesmo neste caso, entretanto, a gestão privada tenderá a ser a mais adequada, desde que acompanhada por um seguro sistema de regulação.

(Plano Diretor da Reforma do Aparelho de Estado, pp. 43-44) 
A reforma gerencial partiu do pressuposto de que há setores em que a atuação exclusiva do Estado não seria imprescindível ou mesmo necessária, abrindo espaço para setores privados, particulares, chamados de "privados não lucrativos" ou "públicos não estatais". Seu principal mentor no Brasil, o então ministro Bresser-Pereira, descartara inspiração neoliberal do projeto, mesmo essa iniciativa tendo sido sustentada por um governo - FHC - cujos pilares eram claramente vinculados a essa corrente ideológica. Mais ainda, o gerencialismo, como se disse, advém da New Public Management, corrente que se desenvolveu no contexto hegemônico do capitalismo liberal (década de 1990), cuja consolidação se deu com o ocaso do chamado "socialismo real" e das críticas tenazes à social democracia.

0 modelo gerencial refere-se à lógica do consumidor, particularmente do denominado "cidadão consumidor" de bens e serviços públicos, e também da competição entre si de agências e equipamentos estatais para provisão de "serviços internos" ao próprio Estado e, em certos casos, a competição entre agentes públicos e privados para que o "cidadão consumidor" seja "soberano" em sua "escolha". Aqui, a lógica da suposta "soberania do consumidor" é transposta ao Estado.

Portanto, mesmo que o gerencialismo tenha aparecido como alternativa à burocratização excessiva do Estado e da prestação de serviços públicos, por meio da promessa de se preocupar primordialmente com os resultados das ações públicas do que com os "meios", tais promessas ou não se cumpriram ou simplesmente implicaram espécie de "governo empresarial" , tal como, reitere-se, definido por Dardot e Laval (2016, p. 272):
[...] o neoliberalismo não procura tanto a "retirada" do Estado e a ampliação dos domínios da acumulação do capital quanto a transformação da ação pública, tornando o Estado uma esfera que também é regida por regras de concorrência e submetida a exigências de eficácia semelhantes àquelas a que se sujeitam as empresas privadas.

0 "governo empresarial" adequar-se-ia, portanto, aos pressupostos do mercado para exercer suas funções "públicas", incluindo a provisão de bem-estar social, vista - não sem contradições e particularidades regionais - à luz das "boas práticas" e da "boa governança". Nesse aspecto, tanto o Estado é enquadrado, em termos fiscais, orçamentários, contábeis e operacionais, ao sentido de eficácia e eficiência do setor privado (isto é, como lógicas do lucro), como este último (com ou sem fins lucrativos formais, pouco importa) passa a fazer parte direta da prestação dos serviços, tal como o gerencialismo indica.

Ainda segundo Dardot e Laval (ibid., p. 276):

A homogeneidade dos modos de pensar, a semelhança dos instrumentos de avaliação e validação das políticas públicas, as auditorias e os relatórios dos consultores, tudo indica que a nova maneira de conceber a ação governamental deve muito à lógica gerencial predominante nos grandes grupos multinacionais.

Dessa forma, o Estado estaria se reconfigurando segundo lógicas privadas, empresariais: finanças e orçamento, ferramentas gerenciais, indicadores, métricas e as referidas conceituações de eficácia e eficiência das políticas públicas e dos cidadãos como consumidores de bens e serviços públicos. Por fim, ressalte-se que, segundo os autores: 
A política que ainda hoje é chamada de "social" por inércia semântica não se baseia mais em uma lógica de divisão dos ganhos de produtividade destinada a manter um nível de demanda suficiente para garantir o escoamento da produção em massa: ela visa a maximizar a utilidade da população, aumentando sua "empregabilidade" e sua produtividade, e diminuir seus custos, com um novo gênero de política "social" que consiste em enfraquecer o poder de negociação dos sindicatos, degradar o direito trabalhista, baixar o custo do trabalho, diminuir o valor das aposentadorias e a qualidade da proteção social em nome da "adequação à globalização". (Ibid., p. 284)

Logo, as "políticas públicas" e o Estado de "bem-estar", embora mantenham essas denominações, em verdade expressam outros significados: o apoio ao "empoderamento do indivíduo" em busca de vencer pelos seus próprios "méritos". Daí a lógica coletiva ser desvalorizada, assim como os conflitos e as estruturas políticas, econômicas e sociais, sempre em nome das saídas individuais. A razão prática e o utilitarismo orientariam as "novas" (em verdade, velhas) políticas. 0 gerencialismo seria a expressão dessas premissas e lógicas tanto nas atividades-meio como nas atividades-fim do Estado. ${ }^{6}$

Por fim, o golpe de Estado vigente no Brasil desde 2016 tem se utilizado fartamente do discurso "modernizante" para privatizar, conceder, transferir, desnacionalizar, contratualizar, para agentes privados nacionais e internacionais, riquezas, bens e serviços antes pertencentes ao Estado ou a agentes nacionais. Ao mesmo tempo, a EC 55 e a reforma trabalhista/ terceirização irrestrita, aprovadas no Congresso Nacional, desestruturam respectivamente os direitos sociais (educação, saúde e assistência social) e os direitos trabalhistas (precarização, terceirização, estrangulamento dos sindicatos, diminuição profunda da Justiça do Trabalho, ausência de garantias trabalhistas). A partir da "eleição" de Jair Bolsonaro, que em verdade implicou "fraude eleitoral", conforme apontado no início, esse processo - verdadeira continuidade do golpe de 2016 - tende a aprofundar-se ao limite.

A seguir são analisados alguns aspectos das respectivas leis das OSs e das Oscips, aprovadas sob $\mathrm{FHC}$, e que ganham maior projeção após a ascensão dos ultraliberais: Temer e Bolsonaro, sem contar estado (como o de São Paulo, por exemplo) e municípios.

Lei $n^{\circ}$ 9.637, de 15 de maio de 1998:

CAPÍTULO I

DAS ORGANIZAÇÕES SOCIAIS

Seção I

Da Qualificação

Art. $1^{\circ}$. 0 Poder Executivo poderá qualificar como organizações sociais pessoas jurídicas de direito privado, sem fins lucrativos, cujas atividades sejam dirigidas ao ensino, à pesquisa científica, ao desenvolvimento tecnológico, à proteção e preservação do meio ambiente, à cultura e à saúde, atendidos aos requisitos previstos nesta Lei.

Art. $2^{\circ}$. São requisitos específicos para que as entidades privadas referidas no artigo anterior habilitem-se à qualificação como organização social:

I - comprovar o registro de seu ato constitutivo, dispondo sobre:

a) natureza social de seus objetivos relativos à respectiva área de atuação;

b) finalidade não lucrativa, com a obrigatoriedade de investimento de seus excedentes financeiros no desenvolvimento das próprias atividades; 
c) previsão expressa de a entidade ter, como órgãos de deliberação superior e de direção, um conselho de administração e uma diretoria definidos nos termos do estatuto, asseguradas àquele composição e atribuições normativas e de controle básicas previstas nesta Lei;

d) previsão de participação, no órgão colegiado de deliberação superior, de representantes do Poder Público e de membros da comunidade, de notória capacidade profissional e idoneidade moral;

e) composição e atribuições da diretoria;

f) obrigatoriedade de publicação anual, no Diário Oficial da União, dos relatórios financeiros e do relatório de execução do contrato de gestão;

g) no caso de associação civil, a aceitação de novos associados, na forma do estatuto; h) proibição de distribuição de bens ou de parcela do patrimônio líquido em qualquer hipótese, inclusive em razão de desligamento, retirada ou falecimento de associado ou membro da entidade;

II - haver aprovação, quanto à conveniência e oportunidade de sua qualificação como organização social, do Ministro ou titular de órgão supervisor ou regulador da área de atividade correspondente ao seu objeto social e do Ministro de Estado da Administração Federal e Reforma do Estado.

Seção III

Do Contrato de Gestão

Art. $5^{\circ}$ Para os efeitos desta Lei, entende-se por contrato de gestão o instrumento firmado entre o Poder Público e a entidade qualificada como organização social, com vistas à formação de parceria entre as partes para fomento e execução de atividades relativas às áreas relacionadas no art. $1^{\circ}$.

Art. $6^{\circ} 0$ contrato de gestão, elaborado de comum acordo entre o órgão ou entidade supervisora e a organização social, discriminará as atribuições, responsabilidades e obrigações do Poder Público e da organização social.

Parágrafo único. 0 contrato de gestão deve ser submetido, após aprovação pelo Conselho de Administração da entidade, ao Ministro de Estado ou autoridade supervisora da área correspondente à atividade fomentada.

Art. $7^{\circ} \mathrm{Na}$ elaboração do contrato de gestão, devem ser observados os princípios da legalidade, impessoalidade, moralidade, publicidade, economicidade e, também, os seguintes preceitos:

I - especificação do programa de trabaIho proposto pela organização social, a estipulação das metas a serem atingidas e os respectivos prazos de execução, bem como previsão expressa dos critérios objetivos de avaliação de desempenho a serem utilizados, mediante indicadores de qualidade e produtividade;

II - a estipulação dos limites e critérios para despesa com remuneração e vantagens de qualquer natureza a serem percebidas pelos dirigentes e empregados das organizações sociais, no exercício de suas funções.

Parágrafo único. Os Ministros de Estado ou autoridades supervisoras da área de atuação da entidade devem definir as demais cláusulas dos contratos de gestão de que sejam signatários.

Como se observa, a lei das Organizações Sociais (OSs) atribui amplo leque de possibilidades de atuação de agentes privados à prestação de serviços públicos. Embora devam se caracterizar como entidades "sem fins lucrativos", em verdade esse instrumento permitiu que vários grupos lucrativos constituíssem OSs que, dessa forma, não estariam voltadas ao lucro. Contudo, são vinculadas e existem em razão de sua matriz lucrativa. Logo, as OSs tornaram-se braços de empresas e 
grupos empresariais, em meio a entidades tipicamente "filantrópicas", atuando com extrema desenvoltura junto à administração pública e nas diversas etapas das políticas públicas. A área de saúde, em diversos municípios e estados - casos de São Paulo, por exemplo -, configura-se como um dos casos em que a saúde "pública" - à luz de Dardot e Laval - é, de fato, viabilizada por entidades privadas por meio de critérios muitas vezes "não públicos". Em outras palavras, embora os recursos sejam públicos (provindos do Sistema Único de Saúde), os instrumentos de gestão, de contratação e de prestação de serviços são essencialmente privados, privatismo este ancorado em tradições e culturas organizacionais empresariais e gerenciais distintas e pouco controláveis, tanto social como efetivamente. Nos regimes urbanos, nas mais diversas áreas, o ambiente é essencialmente similar a esse.

Especificamente quanto aos contratos de gestão, representam justamente o instrumento jurídico que habilita os agentes privados em sua prestação "pública" de serviços. Contêm mensuradores de eficiência, eficácia e efetividade provindos do setor privado, e que não são acordados com as populações às quais os serviços se destinam. Representam o locus tecnocrático/gerencial - espécie de "insulamento burocrático" - cujos "instrumentos de gestão" são tomados como inquestionáveis.

Já, em relação às Organizações da Sociedade Civil de Interesse Público (Oscips), alguns aspectos da lei são assim caracterizados.

Lei no 9.790, de 23 de março de 1999. CAPÍTULO I DA QUALIFICAÇÃO COMO ORGANIZAÇÃO DA SOCIEDADE CIVIL DE INTERESSE PÚBLICO
Art. $1^{\circ}$ Podem qualificar-se como Organizações da Sociedade Civil de Interesse Público as pessoas jurídicas de direito privado sem fins lucrativos que tenham sido constituídas e se encontrem em funcionamento regular há, no mínimo, 3 (três) anos, desde que os respectivos objetivos sociais e normas estatutárias atendam aos requisitos instituídos por esta Lei. (Redação dada pela Lei ${ }^{0} 13.019$, de 2014) (Vigência)

$\S 1^{\circ}$ Para os efeitos desta Lei, considera-se sem fins lucrativos a pessoa jurídica de direito privado que não distribui, entre os seus sócios ou associados, conselheiros, diretores, empregados ou doadores, eventuais excedentes operacionais, brutos ou líquidos, dividendos, bonificações, participações ou parcelas do seu patrimônio, auferidos mediante o exercício de suas atividades, e que os aplica integralmente na consecução do respectivo objeto social. Art. $2^{\circ}$ Não são passíveis de qualificação como Organizações da Sociedade Civil de Interesse Público, ainda que se dediquem de qualquer forma às atividades descritas no art. 30 desta Lei:

I - as sociedades comerciais;

II - os sindicatos, as associações de classe ou de representação de categoria profissional; III - as instituiç̧ões religiosas ou voltadas para a disseminação de credos, cultos, práticas e visões devocionais e confessionais; IV - as organizaçõos partidárias e assemeIhadas, inclusive suas fundações;

$\mathrm{V}$ - as entidades de benefício mútuo destinadas a proporcionar bens ou serviços a um círculo restrito de associados ou sócios;

$\mathrm{VI}$ - as entidades e empresas que comercializam planos de saúde e assemelhados; VII - as instituições hospitalares privadas não gratuitas e suas mantenedoras;

VIII - as escolas privadas dedicadas ao ensino formal não gratuito e suas mantenedoras; 
IX - as organizações sociais;

$X$ - as cooperativas;

XI - as fundações públicas;

XII - as fundações, sociedades civis ou associações de direito privado criadas por órgão público ou por fundações públicas; XIII - as organizações creditícias que tenham quaisquer tipo de vinculação com 0 sistema financeiro nacional a que se refere 0 art. 192 da Constituição Federal.

Art. $3^{\circ} \mathrm{A}$ qualificação instituída por esta Lei, observado em qualquer caso, o princípio da universalização dos serviços, no respectivo âmbito de atuação das Organizações, somente será conferida às pessoas jurídicas de direito privado, sem fins lucrativos, cujos objetivos sociais tenham pelo menos uma das seguintes finalidades:

I - promoção da assistência social;

II - promoção da cultura, defesa e conservação do patrimônio histórico e artístico; III - promoção gratuita da educação, observando-se a forma complementar de participação das organizações de que trata esta Lei;

IV - promoção gratuita da saúde, observando-se a forma complementar de participação das organizações de que trata esta Lei;

V - promoção da segurança alimentar e nutricional;

VI - defesa, preservação e conservação do meio ambiente e promoção do desenvolvimento sustentável;

VII - promoção do voluntariado;

VIII - promoção do desenvolvimento econômico e social e combate à pobreza; IX - experimentação, não lucrativa, de novos modelos socioprodutivos e de sistemas alternativos de produção, comércio, emprego e crédito;

$X$ - promoção de direitos estabelecidos, construção de novos direitos e assessoria jurídica gratuita de interesse suplementar; XI - promoção da ética, da paz, da cidadania, dos direitos humanos, da democracia e de outros valores universais;
XII - estudos e pesquisas, desenvolvimento de tecnologias alternativas, produção e divulgação de informações e conhecimentos técnicos e científicos que digam respeito às atividades mencionadas neste artigo.

XIII - estudos e pesquisas para o desenvolvimento, a disponibilização e a implementação de tecnologias voltadas à mobilidade de pessoas, por qualquer meio de transporte. (Incluído pela Lei $n^{0} 13.019$, de 2014) (Vigência)

A lei das Oscips segue em larga medida as mesmas premissas e os mesmos preceitos das OSs, embora se destinem mais especificamente a entidades de pequeno porte, tais como as organizações não governamentais. Ambas se configuram como os "modernos" instrumentos de gestão privada gerencial e, articuladas às Parcerias Público-Privadas (PPPs) e aos regimes de consorciamento urbanos, transformam a governança dos regimes urbanos, notadamente nas metrópoles, e grande parte das políticas públicas, em extensão dos negócios privados. Embora submetidas aos controles formais dos Tribunais de Contas, tanto sua seleção pelo Poder Executivo quanto o exame de seus modus operandi são extremamente frágeis. Mais importante, sua real contribuição à sociedade, que poderia ocorrer pela via da participação popular e do chamado "controle social", de tal forma que os próprios "instrumentos e métricas de gestão" pudessem ser acordados, essencialmente não ocorre, como apontamos. Isso se dá nas mais diversas áreas de atuação das OSs e Oscips. Conforme se observa na lei, acima, é extenso o leque de atividades nas quais as Oscips podem operar, demonstrando a amplitude da privatização do Estado brasileiro. 


\section{0 sistema político privatizado e sua influência à administração pública e às políticas públicas}

Anteriormente à progressiva privatização da administração/políticas públicas, a transição democrática do final da década de 1980 ocorrera pelo "alto", fazendo-se inteiramente o velho mote do conservadorismo: "mudar para que efetivamente nada mudasse". Algumas características moldaram, desde o início, a arquitetura do que viria a ser a democracia brasileira, isto é, eminentemente privatizada, tendo no mote "transição lenta, gradual e segura" da década de 1970 o vetor que se mantém como fator explicativo para o histórico elitismo da vida política nacional, assim como o golpe de 2016 e seus desdobramentos. Vejamos alguns aspectos. ${ }^{7}$

Embora formalmente o financiamento político seja historicamente misto (público, via fundo partidário, e privado, por meio de doações de empresas e de pessoas físicas), na prática sempre foi largamente privado/ empresarial, tendo em vista o chamado caixa dois. Mas, mesmo o financiamento privado legal, regido por leis e controles, é, por princípio, ilegítimo, em razão da assimetria econômica que impõe à representação política. Em outras palavras, a vida pública tornou-se, desde a "redemocratização", essencialmente organizada pelo poder privado do capital. Além disso, a própria dinâmica do poder implica relações ocultas - que permanecem, mesmo com os avanços nos processos de transparência -, por meio da ampla rede de fornecedores privados e da participação vigorosa dos agentes privados nas políticas e na administração públicas. Isto é, o financiamento privado ilegal não ocorre apenas em períodos eleitorais, pois tende, sobretudo após a "emenda da reeleição" - verdadeiro golpe branco, quanto à forma e ao momento em que foi instaurado, desferido contra a democracia pelo governo $\mathrm{FHC}$-, a fazer parte do cotidiano de quem assume o poder, excetuados os que lutam contra a roldana do sistema.

Somente em fins de 2015 o STF proibiu o financiamento privado empresarial, tendo significado talvez a única ação democrática significativa da alta corte nos últimos anos. Significativamente, contudo, já sob o governo de Temer, o Congresso Nacional aprovou a chamada "minirreforma eleitoral" que permitiu o financiamento individual (dos milionários e bilionários) de forma ilimitada, deixando, contudo, inertes os sistemas de controle. Logo, conseguiu piorar o que já era historicamente privado e assimétrico.

Embora, em tese, a existência potencial de diversos partidos seja fundamental à democracia, uma vez que pode permitir a expressão de interesses e visões de mundos distintos, 0 multipartidarismo criado ao final da ditadura objetivava justamente a pulverização das forças políticas de oposição, de tal modo que não tivessem poder suficiente para derrotar o status quo civil-militar e promover grandes mudanças político/econômicas/sociais. Consolidada a retirada dos militares da cena política, o multipartidarismo teve outros objetivos, para além da pluralidade político-ideológica demandada pelos defensores da democracia, isto é: 1) a necessidade de formação de alianças eleitorais, em larga medida não programáticas, tendo em vista a soma do tempo de rádio e TV referente à propaganda eleitoral; 2) a coalizão, 
incluindo-se partidos derrotados nas eleições, para a composição de maiorias após a vitória eleitoral, igualmente não programáticas, com vistas a constituir "base governista" ampla e capaz de aprovar medidas de governo; 3) o chamado "balcão de negócios", em que barganhas dos referidos tempos no rádio e TV e na formação de alianças, assim como todo tipo de "varejo" parlamentar perante o Executivo, tornaram-se o modus operandi da vida política; e 4) a fragilização dos partidos políticos como agentes de representação social popular. Tudo isso implica a desvalorização dos partidos enquanto instituição, com a consequente personificação política, cuja consequência é a desmobilização coletiva, bem como a pulverização e fragmentação da representação partidária.

Esse conjunto de características pode ser sintetizado no conceito "presidencialismo de coalizão", que representou nada mais que 0 arranjo institucional voltado à "conciliação de classes", no sentido de impedir maiorias populares, moldando de forma conservadora os governos. Os governos petistas jogaram esse jogo exaustivamente, até que, na primeira oportunidade, as elites romperam a conciliação, tanto por não mais precisarem desse instituto como por vislumbrarem a possibilidade de desestruturação dos direitos sociais e trabaIhistas, entre outros.

Além disso, o Parlamento vem sendo fortemente solapado em sua legitimidade. A destituição dos poderes do Parlamento quanto à proposição da "agenda política" e de políticas públicas transformadoras, em contraste ao potencial locus de representação plural e particularmente popular, é parte do projeto de dominação "pelo alto". A chamada "crise do Parlamento" é, dessa forma, estratégica para o jogo das elites, uma vez que o rebaixamento do Legislativo implica hipertrofia do Executivo, em que a tomada de decisão é infinitamente mais rápida, informal e, sobretudo, controlável por lobbies empresariais, os mesmos que financiam - legal e/ou ilegalmente os partidos políticos.

Por fim, em termos institucionais, o baixo controle social dos cidadãos, especialmente os mais pobres, dos representantes eleitos, cujo mandato é apropriado pelos eleitos, faz da representação política arena de negociação distante e muitas vezes em oposição aos interesses populares. Portanto, quanto mais distante do cidadão comum, mais privatizado e elitista torna-se o sistema político. De certa forma, a judicialização das políticas públicas e, mais ainda, a partidarização do Poder Judiciário - notadamente após a Operação Lava Jato - distanciam mais ainda os interesses coletivos populares do "controle social" sobre a tomada de decisão, em benefício dos que transitam pelo poder. Daí ser decorrência o bloqueio dos avanços à institucionalização da participação ocorridos parcialmente a partir do governo Lula, demonstrando que, embora estruturalmente antipopular, há espaço para a participação social nas instituições.

Dessa forma, a junção entre privatização do sistema político e governança neoliberal leva ao radical afastamento dos interesses populares em relação ao "governo empresarial" vigente. 


\section{A financeirização neoliberal e seus impactos na governança das metrópoles}

[...] a implosão do sistema Bretton Woods significou mais do que uma mera mudança nas regras internacionais do jogo monetário e foi acompanhada por transformações profundas que influenciaram tanto a economia quanto o modo de regulação em escala mundial. A troca para um sistema de câmbio flexível (transformando as moedas nacionais em objeto de especulação dos investidores nacionais e internacionais, apostando nas oscilações dos principais preços macroeconômicos, como o câmbio e a taxa de juros), a desregulação e a liberalização dos mercados financeiros nacionais, a criação de novas engenharias financeiras como os derivativos e mercados secundários e, por último, mas não menos importante, a reemergência das finanças globais deixaram profundas marcas nas cidades. Marcas estas apenas parcialmente analisadas pela teoria urbana crítica que emergiu nos anos 1970.

As evidências das articulações entre 0 capital financeiro e o urbano proliferaram-se no cenário pós-Bretton Woods. As complementaridades entre o projeto neoliberal; as políticas de austeridade e o endividamento individual mediado pelo Estado (que reduziu os subsídios para 0 consumo coletivo e fomentou a "inclusão financeira") [..]); a proliferação de estratégias heterodoxas adotadas pelos governos locais para acessar os mercados de capitais - por exemplo, via a antecipação de recursos tributários [...] -; e, mais recentemente, a própria crise subprime [...] mostraram a diversidade de entrelaçamentos entre as cidades e o capital financeiro. 0 ambiente apenas reforçou, se isso ainda fosse necessário, a necessidade de complementar as perspectivas críticas com uma visão mais clara acerca das relações imbricadas entre a moeda, o crédito e as finanças, de um lado, e a dinâmica temporal-espacial das cidades no capitalismo contemporâneo, de outro. (Klink, 2018, pp. 718 e 719)

De acordo com Klink, o mundo das finanças pós-Bretton Woods estaria se efetivando de forma muito mais complexa e aprofundada, na medida em que novos mecanismos financeiros têm sido criados e imiscuídos às práticas urbanas. Novos "empreendedores", que veem no ambiente urbano apenas e tão somente áreas para "investir", por meio de mercados e arranjos urbanos/financeiros novos e distintos, num complexo entre moedas, finanças, mercados, terrenos, negócios e individuação da ação, cujo impacto nas metrópoles é brutal em termos de decisão de onde investir, adensamento, mobilidade e equipamentos públicos e privados, o que implica afetar o ambiente urbano de forma sistêmica e em diversas direções, entre outras consequências.

A governança neoliberal, já potencializada com a presença de atores privados tanto no sistema político como nas atividades-meio (gestão) e fim (políticas públicas) da administração pública, reforça-se ainda mais com o novo universo aberto pelas finanças especulativas que encontra no ambiente urbano, notadamente das metrópoles, solo fértil para sua expansão e aprofundamento. Fecha-se, dessa forma, o círculo privatista, gerencial, neoliberal de aprisionamento do espaço público pelas lógicas, distintas, privadas. 
Mais especificamente, ainda segundo Klink:

De certa forma, a análise crítica das diversas etapas de "entrada da finança" na metrópole [...] pode se beneficiar dos estudos sociais das finanças para desvendar a natureza real de tais disputas. Mais especificamente, a constituição de ativos, a apropriação desigual das métricas utilizadas na precificação e comercialização desses mesmos ativos pelos agentes sociais [...] e, por último, mas não menos importante, 0 entrelaçamento desses processos com o próprio planejamento urbano-metropolitano representa arenas espaço-temporais privilegiadas para construir pontes com a teoria urbana crítica. Uma abordagem dessa natureza poderia também contribuir para lançar luz sobre os descompassos entre modelos e arranjos idealizados de parcerias público-privadas e de instrumentos urbanísticos orientados para o mercado, como a operação urbana consorciada via Certificados de Potencial Adicional de Construção (Cepac), de um lado, e a política urbana efetivamente existente a partir da utilização de determinadas práticas de cálculo, "emprestadas" e adaptadas dos manuais da economia financeira neoclássica, de outro. (Ibid., p. 735)

Em outras palavras, trata-se de nova agenda de pesquisas que se abre a partir de instrumentos de políticas urbanas que têm redesenhado cidades e regiões inteiras, notadamente a partir da articulação de interesses nacionais e internacionais. Os Cepacs, por exemplo, são expressões sintéticas do poder privado sobre a esfera pública por meio de complexos mecanismos financeiros. 0 próprio planejamento urbano torna-se, nesse sentido, vigorosamente ameaçado, uma vez que há enorme gap entre eventuais resultados eleitorais majoritários e o poder - cada vez mais incontrastável - do capital especulativo no ambiente urbano, capital este cada vez mais imbricado com o capital produtivo.

Em paralelo, o papel das referidas PPPs, assim como 0 agendamento público provocado pelas OSs, em particular, em meio ao financiamento empresarial de campanhas, tornam a esfera "pública" destituída de conteúdo, uma vez que "privatizada" pelas diversas frações do capital.

\section{Considerações finais}

Procurou-se, por meio de variáveis confluentes, analisar a substituição, ou melhor, a corrosão, a partir de 1995, dos pressupostos públicos da administração e da gestão públicas devido à introdução progressiva de aspectos da "reforma gerencial", por sua vez configurados em mecanismos, ferramentas e procedimentos gerenciais provindos da administração empresarial. Trata-se, como vimos, de nova realidade do setor público em sua interação com o setor privado, dada a predominância deste último. Afinal, as OSs e as Oscips, ao celebrarem "contratos de gestão" com setores do Estado, impõem, à gestão pública (dimensão administrativa) e às políticas públicas, padrões e métricas que, embora voltados formalmente ao "público", são feitos por meios e, sobretudo, lógicas (conceitos e procedimentos) privados, obedecendo, na prática, aos interesses privatistas desses setores: caso, entre inúmeros outros, dos conceitos de "eficiência" e "eficácia", concebidos à luz dos referidos parâmetros privados. 
As referidas PPPs, a gestão "por resultados" e toda a autonomia que as OSs e Oscips passaram a obter, em termos de recursos financeiros, humanos e administrativos, assim como as formas de atender aos públicos aos quais seus serviços se destinam, descolam-se paulatinamente dos padrões públicos. Em outras palavras, desde a escolha das OSs, a fiscalização financeira/finalística até o "controle social" (que tende a ser baixo, como aludido), o processo não é transparente e tampouco controlável. Essas questões têm transformado substantivamente o Estado brasileiro, impactando vigorosamente a governança - que se torna de outra natureza -, particularmente nas metrópoles e macrometrópole, e necessitam ser investigadas com denodo. Em paralelo, viu-se o papel do grande capital ao financiamento de partidos e campanhas, privatizando-se a vida política, assim como o predomínio das finanças e toda sua complexa matematização em prol de empreendimentos privados que se sobrepõem ao conceito mais elementar de "público".

As hipóteses principais, à luz da discussão acerca da hegemonia, em Antonio Gramsci (2003), e da perpetuação neoliberal contemporânea, em Dardot e Laval (2016), voltam-se à constituição da hegemonia neoliberal (ultraliberal) por dentro do aparelho do Estado, assim como das políticas públicas. No dizer destes últimos autores, representam a "nova razão do mundo" no sentido de introduzirem os referidos pressupostos, ferramentas e práticas sem necessariamente derrogar o Estado e as políticas públicas. Em outras palavras, não é necessário privatizar o Estado, em sentido literal, e sim remodelá-lo segundo os moldes da nova razão procedimental neoliberal.
Por fim, as conclusões deste estudo cuja análise recaiu conceitualmente no âmbito da macrometrópole de São Paulo, mas que pode ser generalizada em larga medida - apontam para novas estratégias do neoliberalismo em perspectiva internacional, isto é, não apenas a velha agenda privatizante, desreguladora e desregulamentadora das relações econômicas e sociais, mas sua convivência com o Estado e as políticas públicas que, contudo, são remodelados, reformatados e redirecionados no sentido de modelarem a gestão "pública" e as políticas "públicas" com contornos privados, gerenciais. Abundam exemplos de rodovias, sistemas de transportes, equipamentos sociais, culturais e científicos, e mesmo presídios, entre outros, concedidos a agentes privados com interesses supostamente "públicos", tornando a esfera pública espécie de sucursal do mundo privado. Essa governança convive e se articula ao sistema político privatizado e antipopular voltado às elites, impedindo a "radicalização" da democracia, isto é, seu aprofundamento participativo e redistributivo em termos políticos e sociais.

Os próprios acontecimentos ocorridos no Brasil desde 2016, que culminaram com a eleição estruturalmente fraudada de Bolsonaro, apenas confirmam esse manancial de novos poderes em prol da agenda liberalizante: algo nunca visto quanto à sua dimensão na sociedade brasileira.

Portanto, deve-se ressaltar que o debate acerca das reformas neoliberais necessita ser refinado, sobretudo quanto ao conceito de "governança" nos regimes urbanos, cujas coalizões são complexas e profissionalizadas a partir do grande capital. É necessário 
compreender a nova "gramática" da gestão pública privatizada, concedida, contratualizada e financeirizada, assim como o papel dos novos atores que habitam a arena pública, na gestão e nas políticas públicas: os proprietários de OSs, Oscips, PPPs e consultorias.

Afinal, a "nova gestão pública" gerencial e financeirizada tem o poder de condicionar, remodelar e adaptar, na prática, a gestão pública e as políticas públicas, mesmo que permaneçam códigos legais como a Constituição, o Direito Administrativo, o Estatuto das Cidades, entre outros, que, contudo, têm sido transformados - em tempos e por meios distintos pela prática neoliberal. São forças opostas que interagem contraditoriamente.

\section{[I] https://orcid.org/0000-0003-4339-4786}

Fundação Getulio Vargas, Escola de Administração de Empresas de São Paulo, Departamento de Gestão Pública, Curso de Administração Pública. São Paulo, SP/Brasil

Pontifícia Universidade Católica de São Paulo, Faculdade de Ciências Sociais, Departamento de Política. São Paulo, SP/Brasil.

franciscocpfonseca@gmail.com

\section{Notas}

(1) Embora tenhamos mantido o termo "neoliberalismo" e suas variantes para definir o padrão de governança metropolitana, em razão de seu domínio comum e, portanto, mais usual, preferimos o termo "ultraliberalismo" e seus correlatos, devido à radicalidade tanto dos diagnósticos como das proposições dessa corrente que, além do mais, demonstra pouco apreço pela democracia política, tal como expresso pelos seus principais ideólogos, notadamente L. Von Mises, F. Von Hayek e M. Friedman, entre outros, em suas inúmeras obras. Para discussão sobre isso, ver Fonseca (2005). Neste artigo, ambos os termos serão utilizados como sinônimos.

(2) No caso brasileiro, o liberalismo econômico é frágil eleitoralmente. Razão pela qual sua ascensão se dar, desde 2016, por meio de golpes: 1) impeachment inconstitucional da presidente Dilma; 2) prisão inconstitucional do ex-presidente Lula - em ambos os casos sem que se comprovasse qualquer crime - com o objetivo, entre outros, de tirá-lo do jogo eleitoral; 3) participação inconstitucional, eminentemente político/ideológica e político/partidária da Operação Lava Jato, em inúmeras dimensões do processo político brasileiro e avalizada pelas cortes superiores, tais como o TRF-4, o TJ e o STF; 4) eleição fraudada de Jair Bolsonaro à presidência da República por meio do uso massivo, ilegal e imoral de mentiras sistêmicas disparadas por empresas altamente profissionalizadas e enviadas por whatsApps, via robôs, especialmente a pessoas vulneráveis a esse tipo de mensagem. Como se sabe, trata-se do mesmo processo coordenado por Steve Bannon nas campanhas de Trump e do Brexit, recentemente trazido ao Brasil. Impressiona o fato de as instituições de justiça no Brasil simplesmente ignorarem esse processo, consolidando, portanto, a fraude eleitoral que, por seu turno, consolida o golpe de 2016. Afinal, Bolsonaro é continuação radicalizada de Temer. 
(3) Pode-se definir esse conceito da seguinte forma: organismos privados que disputam a hegemonia por meio da organização, orientação e veiculação de ideias, valores e interesses.

(4) As tentativas de aplicação das ideias ultraliberais em sociedades reais foram inteiramente fracassadas: tanto pelo voto como pela via da ditadura em perspectiva histórica, casos do Chile sob a ditadura de Pinochet, e da Rússia, sob Boris Yeltsin.

(5) [...] na opinião de Hayek, agiram com regularidade e sucesso como se compreendessem plenamente a posição-chave dos intelectuais e direcionassem seus principais esforços para obter o apoio da "elite", o que certamente era verdade para os fabianos e keynes na Grã-Bretanha. [...]

(6) Com a aprovação, ocorrida no Brasil em 2017, da "terceirização irrestrita" às atividades-meio e também às atividadesfim (estas até então vedadas), tanto ao setor privado como ao setor público, o "governo empresarial" tenderá a se aprofundar vigorosamente a ponto de o aparelho de Estado poder se transformar, no médio prazo e em essência, num universo de prestadores de serviços privados. Dessa forma, o sentido "público" do Estado se esvai com consequências drásticas a tudo que se refira ao público, ao coletivo e ao estatal. Tal medida foi aprovada sob Temer, que somente ascendeu ao poder em razão do referido golpe parlamentar de Estado desferido contra a presidenta legitimamente eleita: Dilma Rousseff. Liberalismo e autoritarismo possuem confluências históricas e evidentes.

(7) Após trinta anos de afastamento formal do poder civil, os militares retornaram à vida política ao sustentarem, com ameaças, a Operação Lava Jato, o que vem implicando a criminalização política do ex-presidente Lula; ao apoiarem vigorosamente a figura pífia e esdrúxula de Bolsonaro; e ao participarem, com cargos de primeiro e segundo escalão, da vida civil brasileira.

\section{Referências}

ABRAMO, P. (2009). Favela e mercado informal: a nova porta de entrada dos pobres nas cidades brasileiras. São Paulo, Antac.

BAHL, R. W. e LINN, J. F. (1992). Urban Public Finance in developing countries. Washington, Oxford University Press.

BAKER, T. e TEMENOS, C. (2015). Urban policy mobilities research: introduction to a debate. International Journal of Urban and Regional Research, v. 39, n. 4, pp. 824-827.

BERNDT, C. e BOECKLER, M. (2009). Geographies of Circulation and Exchange: construction of markets. Progress in Human Geography, v. 33, pp. 535-551.

BRANDÃO, C. A.; FERNÁNDEZ, V. R. e RIBEIRO, L. C. de Q. (2018). Escalas espaciais, reescalonamentos e estatalidades: lições e desafios para América Latina. Rio de Janeiro, Observatório das Metrópoles e Letra Capital. 
BRESSER-PEREIRA, L. C. (1995). Plano Diretor da Reforma do Aparelho do Estado. Brasília, Governo Federal. Disponível em: http://www.bresserpereira.org.br/Documents/MARE/PlanoDiretor/ planodiretor.pdf. Acesso em: 30 jul 2018.

BRITTO, A. L. e REZENDE, S. C. (2017). A política pública para os serviços urbanos de abastecimento de água e esgotamento sanitário no Brasil: financeirização, mercantilização e perspectivas de resistência. Cadernos Metrópole. São Paulo, v. 19, n. 39, pp. 557-581.

CANETTIERI, T. (2017). A produção capitalista do espaço e a gestão empresarial da política urbana: o caso da PBH Ativos S/A. Revista brasileira de estudos urbanos e regionais, v. 19, n. 3, pp. 513-529.

CHRISTOPHERS, B. (2015). The limits to financialization. Dialogues in Human Geography, v. 5, n. 2, pp. 183-200.

COCKETT, R. (1995). Thinking the unthinkable: think-tanks and the economic counter-revolution, 19311983. Londres, Harper Collins.

DARDOT, P. e LAVAL, C. (2016). A nova razão do mundo - ensaio sobre a sociedade neoliberal. São Paulo, Boitempo.

FIX, M. (2011). Financeirização e transformações recentes no circuito imobiliário no Brasil. Tese de Doutorado. Campinas, Universidade Estadual de Campinas.

FONSECA, F. (2005). O consenso Forjado - a grande imprensa e a formação da agenda ultraliberal no Brasil. São Paulo, Hucitec.

GOTHAM, K. F. (2009). Creating liquidity out of spatial fixity: the secondary circuit of capital and the subprime mortgage crisis. International Journal of Urban and Regional Research, v. 33, n. 2.

GRAMSCI, A. (2003). Cadernos do Cárcere. Rio de Janeiro, Civilização Brasileira.

HARVEY, D. (1982). Limits to capital. Oxford, Basil Blackwell e Chicago, University of Chicago Press.

HAYEK, F. A. von (1983). Os fundamentos da liberdade. Brasília, EdUnb e São Paulo, Visão.

(1985). Direito, legislação e liberdade: uma nova formulação dos princípios liberais de justiça e economia política. São Paulo, Visão.

(1987). O caminho da servidão. Rio de Janeiro, Expressão e Cultura Instituto Liberal.

HELLEINER, E. (1994). States and the re-emergence of global finance: from Bretton Woods to the 1990 s. Itaca e Londres, Cornell University Press.

KLINK, J. e BARCELLOS DE SOUZA, M. (2017). Financeirização, conceitos, experiências e a relevância para o campo do planejamento urbano brasileiro. Cadernos Metrópole. São Paulo, v. 19, n. 39.

KLINK, J. (2018). Metrópole, Moeda e Mercados. A agenda urbana em tempos de reemergência das finanças globais. Cadernos Metrópole. São Paulo, v. 20, n. 43, pp. 717-742. Disponível em: http://cadernosmetropole.net/system/edicoes/arquivos/000/000/049/original/Book_CM43. pdf?1544811334.

LAPAVITSAS, C. (2011). Theorizing financialization. Work, employment and society, v. 24, n. 4, pp. 611-626.

PAES DE PAULA, A. P. (2005). Por uma nova gestão pública: limites e potencialidades da experiência contemporânea. Rio de Janeiro, FGV. 
PEDROSA DE OlIVEIRA, A. C. (2016). Dinâmica Política e Política de Gestão: partidos de esquerda e a adoção das parcerias com Organizações Sociais no Brasil - 2007 a 2015. Tese de Doutorado. São Paulo, Fundação Getulio Vargas.

PLANO Diretor da Reforma do Aparelho de Estado. Disponível em: http://www.bresserpereira.org.br/ Documents/MARE/PlanoDiretor/planodiretor.pdf). Acesso em: 30 jul 2018.

RIBEIRO, L. C. de Q. e DINIZ, N. (2017). Financeirização, mercantilização e reestruturação espaçotemporal: reflexões a partir do enfoque dos ciclos sistêmicos de acumulação e da teoria do duplo movimento. Cadernos Metrópole. São Paulo, v. 19, n. 39, pp. 351-378.

(2018). A Metrópole em Questão: desafios da transição urbana. Rio de Janeiro, Letra Capital.

ROYER, L. (2014). Financeirização da Política Habitacional: limites e perspectivas. São Paulo, Annablume.

Texto recebido em $3 / \mathrm{dez} / 2018$

Texto aprovado em 2/mar/2019 
